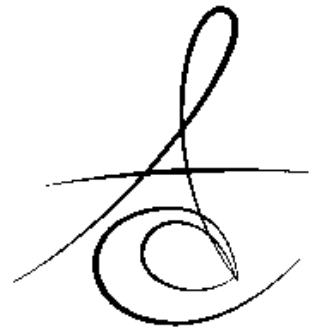

\title{
DİŞ HEKİMLİĞİNDE KULLANILAN REMİNERALİZASYON AJANLARI VE ÇÜRÜK ÖNLEYİCI AJANLAR
}

\section{REMINERALIZATION AGENTS AND CARIES PREVENTIVE AGENTS USED IN DENTISTRY}

Arş. Gör. Dt. Selçuk SAVAŞ*

Yrd. Doç. Dr. Ebru KÜÇÜKYILMAZ*

Makale Kodu/Article code: 1323

Makale Gönderilme tarihi; 24.09.2013

Kabul Tarihi: 23.10 .2013

\section{ÖZET}

Diş çürükleri birçok ülkede önemli bir halk sağlığı sorunudur. Bu nedenle çürük çalışmalarının odak noktası diş çürüğünün önlenmesi ve başlangıç çürüklerinin remineralizasyonuna doğru yönelmiştir. Her ne kadar diş çürüğü ilerleyici tarzda seyir gösteren bir hastalık olsa da, erken aşamada durdurulabilir ve kavitasyon oluşmadan remineralize edilebilir niteliktedir. Klinik uygulamalarda; iyon teknolojileri, biyoaktif ajanlar, şeker alkolleri, bitkisel ajanlar ve kalsiyum fosfat kaynaklı ajanlar gibi birçok remineralizasyon ajanı ve çürük önleyici ajan kullanılmaktadır. Bu derlemede çürük önleyici ajanlar ve remineralizasyon ajanları hakkındaki bilgiler incelenmiş ve konu ile ilgili çalışmaların açıklanması amaçlanmıştır.

Anahtar Kelimeler: Mine remineralizasyonu, remineralizasyon ajanları, çürük önleyici ajanlar

\section{ABSTRACT}

Dental caries is a major public health problem in most countries. For this purpose, the focus in caries research has recently shifted to prevention of dental caries and remineralization of incipient carious. Although dental caries is a disease characterized progressive manner, it can be stopped at an early stage and can be remineralized before a cavitation ocur. There are several remineralization agents and caries preventive agents used in dental practice, such as ionic technologes, bioactive agents, sugar alcohols, herbal agents and calcium-phosphate based materials. In this review, the informations about caries preventive agents and remineralization agents were examined and aimed to explain the studies on this subjects.

Keywords: Enamel remineralization, remineralization agents, caries preventive agents

\section{GİRİŞ}

Diş çürüğü, diş sert dokularının karyojenik mikroorganizmalar tarafından lokalize yıkımı ile karakterize patolojik bir süreçtir. Birçok gelişmiş ülkede diş çürüğü prevelansı geçmiş yıllara göre azalmış olsa da, günümüzde temel sağlık problemlerinden biri olarak önemini sürdürmektedir. ${ }^{1,2}$

Diş sert dokuları, ağız ortamındaki pH değişim dinamiklerinden sürekli olarak etkilenmektedir. Ağız ortamında $\mathrm{pH}$ seviyesinin minenin hidroksiapatit kristalleri için kritik değer sayılan 5,5'in altına düşmesi, mine yapısında bulunan
Günümüzde kalsiyum ve fosfat iyonlarının çözünerek yapıdan uzaklaşmasına neden olmakta ve diş sert dokularının demineralizasyonu olarak adlandırılan süreç başlamaktadır. ${ }^{2,3}$ Ortam pH'ındaki bu değişiklik diyet karbonhidratlarının varlığında plak bakterileri tarafından üretilen organik asitlerin yarattığı etkiden kaynaklanmak- tadır. Eğer pH seviyesini kritik düzeyde tutan faktörler ortadan kalkmaz ise, mine yapısında bulunan minerallerin fazla miktarda kaybı gözlenerek diş çürüğünün tipik karakteristiği olan mine dokusu kaybı ve kavitasyon meydana gelmektedir. ${ }^{3}$ Mine dokusundaki bu kayıp, pH tekrar normal seviyeye gelene kadar devam etmektedir. Ağız ortamının pH seviyesini düşüren etkenler kısa bir süre için etki eder-

\footnotetext{
* İzmir Katip Çelebi Üniversitesi, Diş Hekimliği Fakültesi, Pedodonti Anabilim Dalı, İzmir, Türkiye
} 
se, pH değerinin tekrar yükselmesi sonucu çözünen iyonlar mine üzerine çökelir ve remineralizasyon olarak adlandırılan süreç meydana gelir. ${ }^{4}$

Son yıllarda, diş çürüğünün patolojik sürecinin anlaşılması ve remineralizasyon ve demineralizasyon süreçlerine etki eden faktörlerin belirlenmesi sayesinde koruyucu uygulamalar ön plana çıkmıştır. Demineralizasyon ve remineralizasyon olarak adlandırılan diş sert dokularında mineral dengesinin değişimini yansıtan iki süreç arasındaki denge, oral çevreyi etkileyen birçok faktör nedeniyle bozulabilmektedir. ${ }^{5}$ Koruyucu uygula maların amacı, demineralizasyonu oluşmadan engellemek veya demineralize olan alanları kavitasyon oluşmadan remineralize ederek diş sert dokularını eski sağlığına kavuşturmaktır. ${ }^{6}$

Günümüze kadar, remineralizasyonda en önemli rolü oynayan Ca ve $P$ iyonlarına tükürüğün doygunluğunu arttırmak suretiyle veya ortamda bulunan bu iyonların diş yüzeyine çökelmesinde katalizör rol oynayacak ideal remineralizasyon ajanını elde edebilmek için pek çok çalışma yapılmıştır. Bunun yanı sıra, diş sert dokularının demineralizasyon sürecini önlemek amacıyla kullanılan materyallerle ilgili de birçok çalışma mevcuttur. Bu derlemenin amacl; diş hekimliğinde kullanılan remineralizasyon ajanları ve çürük önleyici ajanlar ile ilgili bilgilerin tanımlanması ve güncel araştırmaların sunulmasıdır.

\section{REMİNERALİZASYON ÇÜRÜK ÖNLEYİCI AJANLAR}

AJANLARI

VE

Çürük önleyici ajanlar ve remineralizasyon ajanları, içeriğinde bulunan kimyasal olarak aktif bileşiğe ya da özel üretim yöntemlerine göre sınıflandırılmaktadırlar. Buna göre materyaller, mineral ve iyon teknolojileri, şeker alkolleri, bitkisel kaynaklı ajanlar, biyoaktif materyaller ve nanoteknolojik ürünler ile diğer kalsiyum ve fosfat kaynaklı remineralizasyon ajanları olmak üzere beş temel başlıkta toplanabilir.

\section{A. Mineral ve İyon Teknolojileri \\ 1.Flor İyonu}

Günümüzde diş çürüklerini önlemek amacıyla en çok kullanılan materyal olan flor, diş minesi üzerinde çürük önleyici etkisini demineralizasyonu önleyici ve remineralizasyonu arttırıcı birçok yoldan göstermektedir. Pellikıl ve plak formasyonunun önlenmesi, plak mikroorganizmalarının asit üretiminin inhibisyonu, doğal minedeki hidroksiapatit yapısından çürüğe karşı daha dirençli bir yapı olan fluorohidroksiapatit oluşumunun sağlanması, kalsiyum ve fosfat iyonlarının diş yüzeyine çökelmesinin hızlandırılması ve bakterisit özellikleri florun çürük önleyici ve remineralize edici etkisini açıklamaktadır. ${ }^{7,8}$ Flor; sistemik olarak veya topikal olarak uygulanabilmektedir. Günümüzde kabul edilen görüş; topikal olarak uygulanan flor preparatlarının daha etkili olduğu yönündedir. ${ }^{8}$ Bu nedenle tükürük ve dental plakta flor iyonu varlığı demineralizasyonun önlenmesi ve remineralizasyonun sağlanması için önemlidir.

Florun çürük önleyici etkisinin kanıtlanmasıyla beraber tek başına flor veya flor ile kombine edilen birçok ürün hakkında detaylı çalışmalar yapılmıştır. Nalbantgil ve arkadaşları ${ }^{9}$ NaF içerikli flor verniklerinin ortodontik braketler çevresinde oluşturdukları etkileri değerlendirdikleri çalışmalarında, verniklerin hem demineralizasyondan korunmada hem de demineralizasyonun geri döndürülmesinde oldukça etkin materyaller olduklarını bulmuşlardır. Yine Alsaffar ve arkadaşları ${ }^{10}$, flor içerikli fissür örtücüler ile konvansiyonel flor içermeyen fissür örtücülerin komşu mine dokusu üzerinde oluşturdukları değişiklikleri değerlendirdikleri çalışmalarında; flor içerikli fissür örtücülerin demineralizasyonu önlemede önemli ölçüde başarıı olduğunu bildirmişlerdir. Rodriques ve arkadaşları ${ }^{11}$, flor salan cam iyonomerlerin demineralize diş sert dokuları üzerindeki etkilerini değerlendirdikleri çalışmalarında, yüksek flor salımı yapan restoratif materyallerin remineralizasyonda daha başarılı sonuçlar verdiğini belirtmişlerdir. Başka bir çalışmada Chu ve arkadaşları $^{12}$ 5-7 yaş arası çocukların anterior dişlerinden başlangıç çürük lezyonuna sahip olanlara 12 ay boyunca düzenli aralıklarla uyguladıkları sodyum florür ve gümüş diamin florür jellerinin etkilerini değerlendirmişler ve 12 ay sonunda demineralizasyonun anlamlı derecede inhibe edildiği ve remineralizasyonun sağlandığı sonucuna varmışlardır. Calvo ve arkadaşları ${ }^{13} \%$ 1,23 asidule fosfat jelin demineralize diş yüzeyine topikal olarak uygulanmasının demineralizasyonun geri döndürülmesinde oldukça etkili bir yöntem olduğunu belirtmişlerdir.

Çalışmaların sonuçları gözden geçirildiğinde flor ve flor bileşikleri, demineralizasyonun inhibisyonu, remineralizasyonun sağlanması, antibakteriyel etkisi ve kolay ulaşılabilirliği ile çürük önleyici programlarda yaygın olarak tercih edilen faydalı materyaller olarak değerlendirilmektedir.

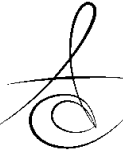




\section{Gümüş İyonu}

Gümüş bileşikleri gümüş nitratın süt dişlerinde çürük insidansının azaltılması amacıyla kullanılmaya başlamasıyla diş hekimliği alanında popülerlik kazanmıştır. Daha sonra daimi dişlerde çürük önleyici ajan, kavite dezenfektanı ve hassasiyet giderici olarak kullanım alanı bulmuştur. ${ }^{14}$ Gümüş iyonu, asidik koşullarda diş sert dokularının çözünürlüğünü azaltması ve demineralize dokuların remineralizasyonunu sağlaması nedeniyle farklı remineralizasyon çalışmalarına konu olmuştur. ${ }^{14-16}$

Zhi ve arkadaşlarının ${ }^{15}$ gümüş ve flor iyonlarını demineralize diş yüzeylerine topikal olarak uygulayarak oluşan etkileri değerlendirdikleri çalışmalarında; her iki iyonun yüzeyde mineral depozisyonu sağladığı, birlikte uygulandıklarında ise remineralizasyon üzerine anlamlı etkilerinin olmadığı bildirilmiştir. Mei ve arkadaşları ${ }^{16}$, \%38'lik gümüş diamin florür solüsyonunun demineralizasyonu önlediğini, mineral kaybını minimale indirdiğini ve karyojenik bakteriler üzerine bakterisit etki gösterdiğini bildirmişlerdir. Gümüş iyonu içerikli primerlerin antibakteriyel etkinliklerinin değerlendirildiği çalışmalarda gümüş içeriğinin gümüş iyonu içermeyen kontrol gruplarına göre antibakteriyel özelliklere katkı sağladığı bildirilmiştir. ${ }^{17,18}$

$\mathrm{Bu}$ çalışmalar göstermiştir ki, gümüş iyonu antibakteriyel oluşu, demineralizasyonun önlenmesi ve remineralizasyonun sağlanması gibi olumlu özellikleri nedeniyle çürük önleyici ve remineralizasyon sağlayan materyaller içerisinde tercih edilebilir niteliktedir. Ancak dişler üzerinde renklenmeye sebep olma özelliği, kullanımını kısıtlayan bir faktör olarak ön plana çıkmaktadır.

\section{Demir İyonu}

Demir eksikliği anemisinin tedavisi amacıyla gıdalara ilave edilen demirin tek başına veya flor, bakır gibi iyonlarla beraber kullanımının çürük önleyici etkisi üzerine yapılan birçok çalışma mevcuttur. ${ }^{19-25}$ Demir iyonunun bu etkisi asidik koşullarda minenin çözünürlüğünün azaltılması, plak pH'ını düşürmesi, oral streptokoklar üzerine bakterisit ve bakteriyostatik etkisinin olması ve streptokokların glikoziltransferaz enzim aktivasyonunu azaltması ile ilişkilendirilmektedir. ${ }^{19-22}$

Pecharki ve arkadaşları ${ }^{19}$, demir iyonunun sukrozun neden olduğu demineralizasyonu inhibe ettiğini ve bu etkinin dental biyofilmdeki streptokokus mutans (MS) formasyonunun baskılanması ile ilişkili olduğunu belirtmişlerdir. Devulapalle ve Mooser'in ${ }^{20} 6 \mathrm{mmol} / \mathrm{L}$ ferrik sülfatı diş yüzeyine topikal olarak uyguladıkları in-vitro çalışmalarının sonucunda, araştırıcılar ferrik sülfat uygulamasının glikoziltransferaz aktivitesini tamamen inhibe ettiğini göstermişlerdir. Rosalen ve arkadaşlarının $^{21}$ konu ile ilgili bir başka çalışması, 10 $\mathrm{mmol} / \mathrm{L}$ demir içeren kolanın diş minesinin çözünmesini in-vitro olarak inhibe ettiğini, bununla beraber demir katkısının diş boyama, tat bozuklukları, toksisite gibi yan etkiler yaratabileceğini göstermektedir. Martinhon ve arkadaşları ${ }^{22}, 15 \mathrm{mmol} / \mathrm{L}$ ferik sülfatın diş minesinin yüzeyinden mineral kaybını azalttığı, bununla birlikte, dental biyofilmde oluşan, çözünebilir polisakkaridler üzerinde bir etki yaratmadığını belirtmişlerdir. Bununla birlikte, Alves ve arkadaşları ${ }^{23} \mathrm{Fe}^{+2}$ içeren solüsyonların konsantrasyonlarının remineralizasyon ve demineralizasyon üzerine etkisini değerlendirdikleri in-vitro çalışmada, $18 \mathrm{mg} \mathrm{Fe} / \mathrm{mL}$ içeren solusyonların kulanımının demineralizasyonu önlemede en başarılı solusyon olduğunu, demineralize lezyonun remineralizasyonunda ise herhangi bir artışa neden olmadığını göstermişlerdir. Yine Hidaka ve arkadaşları ${ }^{24}$, demir iyonlarının Ca ve $\mathrm{P}$ iyonlarının diş yüzeyine çökelmelerini engellediğini bulmuşlardır. Benzer şekilde Guggenbuhl ve arkadaşlarının ${ }^{25}$ yaptığı çalışma da bu bulguları destekler niteliktedir. Bu çalışmalar ışığında, demir iyonunun demineralizasyonu önlediği, antibakteriyel etki gösterdiği fakat demineralize alanların remineralizasyonunda herhangi bir katkısının olmadığı sonucuna ulaşılabilir.

\section{B. Şeker Alkolleri:}

\section{Ksilitol:}

Ksilitol; çeşitli selülozlu ürünlerden elde edilen, oral mikroorganizmalar tarafından metabolize edilemeyen 5 karbonlu bir şeker alkolüdür ve çürük önleyici etkisi nedeniyle uzun yıllardır birçok diş hekimliği ürününde kullanılmaktadır. ${ }^{26}$ Ksilitolün çürük önleyici etkisi hem patolojik bakteriler tarafından fermente edilememesine hem de antibakteriyel özelliklerine bağlanmaktadır. Ksilitollü ürünler kullanan bireylerde tükürük akış hızının arttığı, tükürük akış hızının artmasına bağlı olarak tükürüğün tamponlama kapasitesinin arttığı ve oral çevrenin $\mathrm{pH}$ değerinin yükseldiği bilinmektedir. Ksilitolün yapısında bulunan hidroksil iyonları tükrük sıvısında bulunan $\mathrm{Ca}$ ve $\mathrm{P}$ ile bağlanmakta ve böylece tükrük içerisinde ve ağız ortamında Ca seviyesinin belirli bir düzeyde kalmasını sağlamaktadır. Ksilitolün bakteriler tarafından fermente

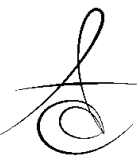


edilememesi asit oluşturan mikroorganizmaların asit üretimini baskılanmasını sağlamakta ve böylece oral çevrenin $\mathrm{pH}$ değerinin düşmesi önlenmektedir ${ }^{27}$. Ayrıca ksilitol ekstrasellüler polisakkarit miktarını azaltmakta ve böylece asidojenik bakterilerin diş yüzeyine yapışmasına engel olmaktadır. ${ }^{28}$

Ksilitol; sakız, diş macunu, ilaçlar, ağız gargaraları gibi birçok ürün içerisinde kullanılabilir niteliktedir ve remineralizasyon kapasitesi ve çürük önleyici etkisi ile ilgili yapılan birçok çalışma mevcuttur. ${ }^{29-31}$

Ksilitolün, mutans streptokokların anne-çocuk geçişini azaltarak çürük önleyici etki gösterdiği yapılan çalışmalarda gösterilmiştir. ${ }^{29}$ Söderling ve arkadaş$\operatorname{ların}^{29} 6$ yıllık klinik takip çalışmalarında, ksilitollü sakız çiğneyen annelerin çocuklarının oral florası incelendiğinde mutans streptokok kolonizasyonunda ve 5 ylllık gözlem periyodunun sonunda çürük prevelansında anlamlı derecede azalma görülmüştür. Çalışmanın sonuçları ksilitolün bakteriyel transfer ve kolonizasyonu inhibe ettiğini göstermiştir. Başka bir çalışmada Loesche, günde 5-7 gr ksilitolün sakızla beraber tüketiminin hem plak içerisinde hem de tükürükte MS sayısını azalttıklarını bulmuşlardır. Bradshaw ve arkadaşlar ${ }^{31}$, ksilitolün hedef mikroorganizmasının mutans streptokoklar olduğunu bildirmişlerdir. Gaffar ve arkadaşları ${ }^{32}$, ksilitol, $\mathrm{NaF}$ ve ksilitol+NaF içerikli diş macunlarının remineralizasyon üzerine etkilerinin inceledikleri çalışmalarında, ksilitol+Flor kombinasyonunun tek başına flor ya da tek başına ksilitol içeren diş macunlarından anlamlı derecede daha fazla remineralizasyon meydana getirdiğini bulmuşlardır.

Tüm bu çalışmaların ışığında antibakteriyel etkinliği, tükürük tamponlama kapasitesi üzerine olumlu etkileri ve birçok ürün içerisinde kullanılabilir oluşu nedeniyle ksilitol çürük önleyici ajan olarak günümüzde pek çok ürün içerisinde yerini almış, etkisi kanıtlanmış bir materyaldir.

\section{2. İzomalt:}

Şeker alkolleri içerisinde yer alan izomalt, şekerleme ve sakızlarda sıklıkla kullanılmaktadır ve oral bakteriler tarafından fermente edilemediğinden nonkaryojenik ve non-asidojenik sınıfina girmektedir. ${ }^{33}$ İzomaltın $\mathrm{Ca}$ bağlayıcı özelliği çürük önleyici, remineralizasyonu etkileyebilecek bir ürün olarak değerlendirilmesine olanak sağlamıştır. ${ }^{34}$ Takatsuka ve arkadaşları ${ }^{35}$, izomalt içerikli diş macunu ve ağız çalkalama solusyonlarının mine remineralizasyon ve demineralizasyonu üzerine etkilerini in-situ ve in-vitro olarak değerlendirdikleri çalışmalarında, izomaltın remineralizasyon sürecinde olumlu etki yarattığını, bununla beraber asıl etkisini flor ile birlikte kullanııldığında gösterdiğini bildirmişlerdir. Bu nedenle izomaltın flor içerikli ürünlere ilave olarak kullanılabileceğini önermişlerdir.

\section{Sorbitol:}

Sorbitol, mutans streptokoklar tarafindan fermente edilebilmesine rağmen; sukroz, glikoz ve früktoz gibi diyet şekerleri ile kıyaslandığında üretilen asit oranı anlamlı olarak daha azdır ${ }^{36}$, bu nedenle nonkaryojenik şeker olarak adlandırımaktadır. ${ }^{37}$ Ancak bu yapay şekeri ksilitol ile kıyaslayan çalışmalar incelendiğinde ksilitolün daha üstün olduğu söylenebilir. Örneğin; Splieth ve arkadaşları ${ }^{38}$, ksilitol ve sorbitol içerikli pastil kullanan bireylerin plak asidojenitesinde oluşan değişiklikleri incelediklerinde, ksilitol içerikli pastil kullanan bireylerin sorbitol içerikli pastil kullanan bireylere oranla plak pH'ında anlamlı derecede azalma olduğunu bildirmişlerdir. Aynı şekilde, Thorild ve arkadaşlarını ${ }^{39}$ yeni doğan bebeklerin annelerine tek başına ksilitol, sorbitol+ ksilitol+ klorheksidin ve sorbitol+ksilitol+flor içerikli diş macunları çiğneterek anne-çocuk oral flora geçişi ve çocuklardaki etkilerini inceledikleri çalışmalarında, en başarılı grubun tek başına ksilitol grubu olduğunu bildirmişlerdir.

Bu çalışmalar ışığında, sorbitolün çürük önleyici materyal olarak kullanılabilir olduğu fakat bu etkisinin ksilitol ile kıyaslandığında daha az olduğu görülmektedir.

\section{Bitkisel Kaynaklı Ajanlar \\ 1. Kitosan:}

Doğada bulunan kitinin deasetilasyonu sonucu elde edilen bir biyopolimer olan kitosan, bakteriostatik ve bakterisit özellikleri nedeniyle diş çürüklerinin önlenmesi amacıyla kullanılmaktadır. Ayrıca kitosan oral kavitede $\mathrm{pH}$ değerlerini düşüren organik asitlerin etkilerini tamponlayabilmektedir. ${ }^{40}$

Hayashi ve arkadaşlarına göre ${ }^{41}$, kitosan içerikli sakız çiğneyen bireylerde karyojenik bakterilerin büyümesinin inhibisyona uğramaktadır ve kitosanın bu etkisi yalnızca tükürük akışının stimulasyonun sonucu değil aynı zamanda kitosanın direk bakterisit ve bakterostatik etkisinden de kaynaklanmaktadır. Bu çalışmanın sonuçları sakıza kitosan ilavesinin karyojenik bakterilerin üremesinin kontrolünde başarılı bir ürün olduğunu göstermiştir. Yine aynı şekilde, Uysal ve 
arkadaşları da ${ }^{42}$ kitosan içeren sakız çiğnemenin zayıf oral hijyene sahip hastalarda tükrükteki karyojenik bakteri büyümesini inhibe ettiğini ve mine dekalsifickasyonunu azalttığını bulmuşlardır. Arnaud ve arkadaşları $^{43}$ kitosanın mineden mineral salınmasını inhibe ederek demineralizasyonu önlediğini belirtmişlerdir. Muzzarelli ve arkadaşları ${ }^{44}$ ise kitosanın plak mikroorganizmaları üzerine etkilerini inceledikleri çalışmalarında, kitosanın birçok patojenik bakteri üzerinde bakterisit etki gösterdiğini bildirmişlerdir. Fujiwara ve arkadaşlarının ${ }^{45}$ kitosanın farklı konsantrasyonlarda kullanımının bakteriyel büyüme üzerine etkilerini irdeledikleri çalışmalarında, \%2'lik kitosan solüsyonunun optimal konsantrasyon olduğunu ve streptokok mutanslar üzerinde neredeyse tam bir inhibisyon sağladığını göstermişlerdir. Bae ve arkadaşlarına ${ }^{46}$ göre, kitosan ağız çalkalama solüsyonu olarak kullanıldığında, antibakteriyel etkisinin yanında plakta azalmaya da yol açmaktadır.

Çalışmalardan elde edilen sonuçlar bir arada değerlendirildiğinde kitosanın; diş sert dokularının demineralizasyonunu önlemekte etkili olduğu anlaşılmaktadır, remineralizasyon kabiliyeti konusunda ise sınırlı bilgi mevcuttur. Kitosanın bakterisid ve bakteriyostatik etkisi birçok çalışmada gösterilmiştir. Bu nedenle antibakteriyel bir çürük önleyici ajan olarak kullanılması tavsiye edilebilir niteliktedir.

\section{Galla Chinensis (G. Chinensis)}

Bir tür bitkisel ilaç türü olan G. Chinensis özünün çürük için profilaktik amaçla kullanımı bazı çalışmalara araştırma konusu olmuştur. G. chinensis hidrolize tanen bakımından zengindir ve biyolojik etkileri geniş bir alana yayılmaktadır. Remineralizasyon açısından değerlendirildiğinde, diş sert dokularının kristal yapısını etkileyerek olumlu etki yarattığı iddia edilmektedir. ${ }^{47}$

Huang ve arkadaşlarına ${ }^{47}$ göre, nanohidroksiapatit ve G. Chinensisin başlangıç mine lezyonları üzerine etkileri incelendiğinde, hem nanohidroksiapatit hem de G. Chinensis başlangıç çürük lezyonları üzerinde remineralizasyon oluştururken, iki ürünün birlikte kullanımı anlamlı bir sinerjik etki yaratmaktadır. Chu ve arkadaşları ${ }^{48} \mathrm{G}$. Chinensisin kimyasal içeriğinin başlangıç çürükleri üzerine etkilerini değerlendirdiklerinde, G. Chinensisin minede oluşan demineralizasyonu inhibe ettiğini ve diş minesinin remineralizasyonunu arttırdığını bildirmişlerdir. Cheng ve arkadaşları $^{49}$ G. Chinensisin mine yapısı üzerinde etkilerini değerlendirdikleri çalışmalarının sonucunda, G. Chinensisin kimyasal içeriğinin; mine kristallerinin morfolojisini, yapısını ve kimyasal içeriğini etkileyerek demineralizasyon/ remineralizasyon dengesini düzenlediğini bulmuşlardır. Diğer taraftan Xie ve arkadaşları ${ }^{50}$ ise G. Chinensisin florun yarattığı remineralizasyon etkisinden farklı olarak, lezyonun en dış yüzeyinde oluşan remineralizasyonu yavaşlattığını ve böylece lezyon gövdesine iyon transportuna izin verdiğini vurgulamışlardır. Bu nedenle G. Chinensisin flordan farklı bir remineralizasyon sağlayıcı etkisi bulunmaktadır. Ayrıca Huang ve arkadaşları ${ }^{51}$ tarafından G. Chinensis içerikli bir solusyonun çoklu mikrobiyal biyofilmlere etkilerinin değerlendirildiği bir çalışmada; bu solusyonun, alkali pH'da etkili olmadığı, çürük önleyici etkisinin kritik pH değeri olarak kabul edilen 5,5'in altında etki ettiği gösterilmiştir.

Bu çalışmalar, G. Chinensisin hem çürük önleyici bir ajan hem de remineralizasyon ajanı olarak kullanılabileceğini ortaya çıkarmaktadır. Ayrıca florun remineralizasyon mekanizmasından farklı olan mekanizması yüzey altı lezyonların remineralizasyonununda başarılı bir materyal olarak kullanılabileceğini düşündürmektedir.

\section{Teobromin}

Teobromin, teofilin ve kafein benzeri bileşikler içeren metilksantin ailesinden bir alkaloittir ve ana kaynağı kakao bitkisidir. Diş sert dokularının mineralizasyonu üzerine etkileri keşfedildikten sonra birçok çalışma ile çürük önleyici etkisi araştırılmıştır.

Amaechi ve arkadaşları ${ }^{52}$, teobrominin apatit formasyonunu sağlayan özelliği sayesinde remineralizasyonu arttırıc bir etkiye sahip olduğunu bulmuşlardır ve bu etkinin florla kıyaslanabilir nitelikte olduğu sonucuna varmışlardır. Kargül ve arkadaşlar ${ }^{53}$ yaptıkları çalışmada teobrominin mine yüzeyinin korunmasında etkili olduğunu gözlemlemişlerdir. Nakamato ve arkadaşlarının $^{54,55}$ deney hayvanları üzerinde gerçekleştirdikleri çalışmaların sonuçlarına göre; teobromin hem minedeki apatit kristallerinin çözünmeye karşı direncini hem de mine yüzeyinde kristalleşmeyi arttırmaktadır. Çalışmalar teobrominin remineralize edici ve demineralizasyonu önleyici etkisi olduğunu göstermektedir. Diş sert dokularının remineralizasyonu amacıyla kullanılabilecek bir materyal olarak görülmektedir. 


\section{Biyoaktif Nanoteknolojik Ürünler \\ 1. Kalsiyum Sodyum Fosfosilikat (Biyoaktif Cam):}

Son yıllarda diş hekimliğinde kullanım alanı bulan biyoaktif camlar, biyomateryal olarak adlandırılan malzeme grubundandır. Biyoaktif camlar, diş hekimliğinde dentin hassasiyetinin giderilmesi, vital tedaviler, kemik rejenerasyonu, diş sert dokularının remineralizasyonu, antibakteriyel tedaviler gibi birçok alanda kullanılmaktadı. ${ }^{56}$ Diş sert dokularının remineralizasyonu amacıyla değerlendirildiğinde; biyoaktif camlar tükürük ile temas haline geldiğinde, remineralizasyon için kullanılabilir olan sodyum kalsiyum ve fosfor iyonlarının salımı gerçekleşmekte ve bu sayede minenin kompozisyonunu oluşturan hidroksiapatite benzer hidroksikarbon apatit oluşmaktadır. Bu nedenle biyoaktif camların diş hekimliğinde remineralizasyon amacıyla kullanılabileceği düşünülmektedir. ${ }^{57-59}$ Biyoaktif camların partikül boyutları nano seviyelerdedir. Bu özelliği nedeniyle daha hızlı iyon salımı gerçekleştirebilmekte ve biyoaktif özelliği daha belirgin olarak ortaya çıkmaktadır.

Flor içeren ticari bir diş macunu ile flor ve kalsiyum sodyum fosfosilikat ürününün karşılaştırıldı̆ı bir çalışmada kalsiyum sodyum fosfosilikat diş temizleyici ajanın erken dönem çürük lezyonlarında daha yüksek derecede remineralizasyon sağladığı sonucuna varılmıştır. ${ }^{60}$ Dlamanti ve arkadaşları ${ }^{61}$ biyoaktif cam ile sodyum floridin başlangıç çürük lezyonları üzerine etkilerini karşılaştırdıkları çalışmada, biyoaktif camların flora alternatif bir remineralizasyon ajanı olarak kullanılabileceğini bildirmişlerdir. Ayrıca biyoaktif cam kompozisyonunun çürük yapıcı patojen mikroorganizmalar üzerine etkilerinin değerlendirildiğinde materyalin mutans streptokoklar üzerinde anlamlı bir antimikrobiyal etkiye sahip olduğu ve oral çevrenin pH'ını yükselttiği bildirilmiştir. ${ }^{62}$ Bir başka çalışmada ise yapay tükürük ortamında, vücut ısısında biyoaktif cam materyalin apatit tabakası oluşturduğu belirtilmiştir. ${ }^{63}$ Tüm bu çalışmalar göstermiştir ki, kalsiyum sodyum fosfosilikat flora alternatif olarak kullanılabilecek bir çürük önleyici ajan ve remineralizasyon ajanıdır.

\section{Trikalsiyum silikat}

Biyoaktif materyaller olarak adlandırılan malzeme grubunda yer alan trikalsiyum silikat, diş sert dokuları üzerinde apatit formasyonu oluşturma kabiliyeti nedeniyle pek çok araştırmaya konu olmuştur. ${ }^{64,65}$

Trikalsiyum silikat ve 1000 ppm flor içerikli iki ürünün demineralizasyon sürecine etkilerinin kıyaslandığı in-vitro bir çalışmada, flor ve trikalsiyum silikatın benzer etki gösterdiği, kalsiyum silikat materyalinin demineralizasyonu önlemede ve remineralizasyonu arttırmada kullanılabilecek biyoaktif bir kaynak olduğu belirtilmiştir. ${ }^{64}$ Dong ve arkadaşlarını $^{65}$ asitlenmiş mine yüzeyine trikalsiyum silikat içerikli bir pasta kullanımının sonuçlarını inceledikleri çalışmalarında, kalsiyum silikatın mine yüzeyinde apatit formasyonunu indüklediği, mine yüzeyine Ca-P çökelmesini sağladığı ve minenin korunmasında ve yenilenmesinde kullanılabilir bir materyal olduğu gösterilmiştir.

\section{Nano Hidroksiapatit:}

Mine dokusu kompleks bir yapı göstermekle beraber esas olarak 20-40 nm boyutundaki hidroksiapatit nanopartiküllerinden meydana gelmiştir. İlk olarak üretilen sentetik mikrohidroksiapatit materyaller yüksek biyouyumlu özelliğe sahip olmaları ve diş minesiyle benzer kimyasal özellikler göstermeleri nedeniyle remineralizasyon çalışmalarında yer almış materyallerdir. Diğer taraftan mikrohidroksiapatitler diğer kalsiyum fosfat bileşikleriyle kıyaslandığında daha az çözünürlüğe sahiptir. ${ }^{66-69}$ Bu nedenle hidroksiapatitin çözünürlüğünü arttırarak salınan $C a$ ve $P$ iyonlarının oranını arttırmak amacıyla nanohidroksiapatitler geliştirilmiş ve remineralizasyon çalışmaları bu doğrultuda yoğunlaşmıştır.

Lee ve arkadaşları ${ }^{68}$ nano-hidroksiapatit ve mikro-hidroksiapatit içerikli cam iyonomer restoratif materyallerin remineralizasyon üzerine etkilerini incelediklerinde her iki grubun da başlangıç mine lezyonlarının remineralizasyonunu sağladığını, ayrıca nanohidroksiapatit içerikli cam iyonomerin demineralizasyonu önlemede anlamlı derecede fark gösterdiğini ifade etmişlerdir. Bir başka çalışmada, Huang ve arkadaşları $^{69}$ dinamik pH siklusu şartlarında nanohidroksiapatit ve mikrohidroksiapatitin remineralizasyon üzerine etkilerini değerlendirmiş, her iki materyalin de remineralizasyonu arttırdığını, bununla beraber nanohidroksiapatitin mikrohidroksiapatite kıyasla daha fazla olumu etki yarattığını bildirmişlerdir. Nanohidroksiapatit ve aminflorid içerikli diş macunlarının remineralizasyon kapasitelerinin değerlendirildiği in-vitro bir çalışmada, çalışma sonuçları nanohidroksiapatit içerikli diş 
macununun başlangıç çürük lezyonlarının remineralizasyonunda daha başarılı olduğunu göstermiştir. ${ }^{69}$ Huang ve arkadaşları ${ }^{71}$ ise dinamik $\mathrm{pH}$ siklusu koşullarında optimal nanohidroksiapatit konsantrasyonu ve nanohidroksiapatitin başlangıç çürük lezyonları üzerine etkilerini in-vitro olarak değerlendirdikleri çalışmalarında, \%10 nanohidroksiapatit konsantrasyonunun en uygun konsantrasyon olduğunu ve düzenli olarak kullanımının remineralizasyonun teşvikinde yararlı olduğunu göstermişlerdir. Swarup ve $\mathrm{Rao}^{72}$, \%10 nanohidroksiapatit ile $\% 2$ sodyumfloridin remineralizasyon üzerine etkilerini değerlendirdikleri çalışmalarında $20 \mathrm{~nm}$ genişliğindeki nano hidroksiapatit kristallerinin florla kıyaslandığında başlangıç çürük lezyonlarının remineralizasyonunda daha başarılı olduğunu belirtmişlerdir. Bunun yanında, nötral koşullar altında hidroksiapatitin remineralizasyonu tam olarak sağlayamadığını, asidik koşullarda hidroksiapatitin daha fazla çözünerek iyonların salımının ve penetrasyon derinliğinin artarak remineralizasyonu daha hızlı gerçekleştiğini bildirmişlerdir.

Çalışmalara dayanılarak elde edilen veriler, hidroksiapatitin ümit verici bir remineralizasyon ajanı olduğunu göstermektedir.

\section{Kazein Fosfopeptid Amorf Kalsiyum Fosfat (CPP-ACP):}

Kazein fosfopeptid amorf kalsiyum fosfat (CPPACP) kompleksi; tüm hayvansal sütlerin içerisinde yer alan kazein fosfopeptidin, içerdiği fosfoseril uzantılar boyunca amorf kalsiyum fosfatı bağlayarak solüsyon içerisinde çökelmeleri için gerekli boyuta ulaşmalarını engellemesiyle meydana gelmektedir. CCP-ACP çürük önleyici etkisini bakteriyel kolonizasyonu önleyerek, dental plağın Ca ve $P$ seviyesini yükselterek ve serbest Ca ve $P^{\prime} ı$ bağlayarak göstermektedir. ${ }^{72-74}$ Günümüzde CCP-ACP; solusyon, şekersiz sakız, gargara, diş macunu gibi ürünlerde remineralizasyona olan katkıları nedeniyle kullanılmaktadır.

CPP-ACP nanokompleksinin çürük önleyici etkisi birçok çalışmada gösterilmiştir. CPP-ACP içerikli ağız çalkalama sularının in-situ değerlendirildiği bir çalışmada, başlangıç çürük lezyonlarında yüksek oranda remineralizasyonu sağladığı bildirilmiştir. ${ }^{73}$ CPP-ACP içerikli diş macunlarının dentin yüzeyinde oluşturulan başlangıç çürük lezyonları üzerine etkilerinin değerlendirildiği başka bir çalışmada ise, materyalin diş yüzeyinde $\mathrm{Ca}$ ve $\mathrm{P}$ çökelmesi sağlayarak remineralizasyona anlamlı katkıda bulunduğu gösterilmiştir. ${ }^{74}$
CPP-ACP ile yapılan çalışmaların tümü değerlendirildiğinde, yüksek remineralizasyon kabiliyeti, materyalin ulaşılabilirliği ve kolay kullanımı nedeniyle önerilebilecek bir remineralizasyon ajanıdır.

\section{Kazein Fosfopeptid Amorf Kalsiyum Floro Fosfat (CCP-ACFP):}

CCP-ACP ve flor çürük önleme ve remineralizasyon amacıyla birlikte kullanıldıklarında sinerjik etki yaratmaktadır. Reynolds ve arkadaşları yaptıkları çalışmanın sonuçlarına göre \%1 CCP içeren solusyonla 500 ppm flor içeren solusyonun etkilerini değerlendirdiklerinde, birlikte kullanımları sonucu remineralizasyon etkisinin arttığını ve florun \%50 sinin CPPACP'ye bağlandığını bildirmişlerdir. ${ }^{75}$ Araştırıcılar yeni oluşan bileşiği CCP-ACFP olarak tanımlamışlardır. CPP$A C P$ ve $C C P-A C F P$ nin başlangıç çürükleri üzerine etkilerinin kıyaslandığı çalışmanın sonuçlarına göre CCPACFP'nin daha fazla remineralizasyon sağladığı bulunmuştur. CCP-ACP ve florun sinerjik etkisi nedeniyle remineralizasyon amacıyla kullanılması önerilmektedir. ${ }^{76}$

\section{Trikalsiyum Fosfat:}

Trikalsiyum fosfat'ın $\left(\mathrm{Ca}_{3} \mathrm{PO}_{4}\right)_{2}$ alfa ve beta olmak üzere iki formu mevcuttur. Beta formu daha az çözünürdür ve bu nedenle alfa formu yaygın olarak tercih edilmektedir. Alfa trikalsiyum fosfatın ağız ortamındaki serbest $\mathrm{Ca}$ ve $\mathrm{P}$ seviyesini arttırarak diş sert dokularının remineralizasyonunu sağladığı düşünülmektedir. ${ }^{77,78}$

Vogel ve arkadaşları, \%2.5 alfa trikalsiyum fosfat içeren sakızların plak sıvısı ve tükürük içerisindeki Ca ve P seviyelerinde küçük bir artış yarattığını

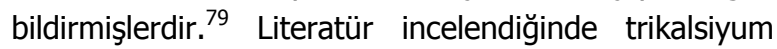
fosfatla ilgili sınırı çalışma bulunmaktadır. Remineralizasyon ajanı olarak kullanılabilmesi için daha kapsamlı çalışmalara gerek duyulmaktadır.

\section{Kendiliğinden Birleşen Peptitler:}

Anyonik peptitlerin, diş sert dokuları üzerinde yarattığı olumlu etkiler nedeniyle remineralizasyon çalışmalarında kullanılabilir nitelikte olduğu düşünülmektedir. Peptitlerin bu etkisi, mineral kaybının azaltılması ve mineral kazancının arttırılması yoluyla gerçekleşmektedir. Geleneksel remineralizasyon ajanlarından farklı olarak, diş yüzeyinde iyonların çökelmesine olanak veren bir iskelet oluşturmaktadırlar ve oluşan bu iskelet yoluyla mineral depozisyonu sağlanmaktadır. ${ }^{80}$ 
Brunton ve arkadaşları ${ }^{81}$, peptitlerin remineralizasyon etkilerini inceledikleri in-vivo çalışmalarında, tek sefer uygulamadan sonra bile anlamlı derecede remineralizasyon sağlandığını belirtmişlerdir. Yazarlar, anyonik peptitlerin diş sert dokularının remineralizasyonunda kullanılabilir olduğunu iddia etmektedirler.

\section{F. Diğer Kalsiyum ve Fosfat Kaynaklı Remineralizasyon Ajanları \\ 1. Dikalsiyum Fosfat Dihidrat (DCPD):}

Dikalsiyum fosfat dihidrat (DCPD) bazı florlu diş macunlarında, flor komponentinin remineralizasyon etkisini arttırmak amacıyla kullanılmaktadır.

Sullivan ve arkadaşlarının ${ }^{82}$ DCPD içerikli diş macunu kullanımının oral çevredeki Ca düzeyi ve plak sıvısındaki Ca aktivitesi üzerine etkilerini değerlendirmek amacıyla yaptıkları in-vivo çalışmanın sonuçlarında, DCPD'li diş macunlarının oral çevreye $\mathrm{Ca}$ iyonu salımı yaptıklarını ve salınan bu Ca'un minede oluşmaya başlamış başlangıç lezyonları için remineralizasyonu sağlayabilir nitelikte olduğunu belirtilmiştir. Plak sIvısındaki etkisi değerlendirildiğindeyse plak sIvisındaki serbest kalsiyum ve fosfat oranını arttırdığını bildirmişlerdir. Bu çalışmanın sonuçları diş macunlarına dikalsiyum fosfat dihidrat formunda $\mathrm{Ca}$ ve $\mathrm{P}$ ilavesinin çürük önleyici etkisinin olduğunu göstermektedir.

Wefel ve Harles ${ }^{83}$ DCPD ve florun diş macunlarında kombine kullanımını değerlendirdikleri çalışmada, DCPD ve flor arasında pozitif bir etkileşim olduğunu ve kombine kullanım ile florapatit formasyonunun daha fazla geliştiği, remineralizasyonun daha hızlı gerçekleştiğini bildirmişlerdir.

Zhang ve arkadaşlar ${ }^{84}$ DCPD+ sodyummonoflorofosfat, DCPD placebo ve 1000 ppm sodyummonoflorofosfat kullanarak yaptıkları klinik çalışmada, DCPD+sodyummonoflorofosfat+flor grubunun, florun tek başına yarattığı etkiden daha fazla antikaryojenik etki yarattığını bildirmişlerdir.

Bu çalışmaların ışığında görülmektedir ki, DCPD flor ile olumlu bir etkileşime girerek remineralizasyonun daha hızlı olmasını sağlamaktadır. Bu nedenle florlu diş macunları içerisine katkı olarak kullanılabilecek nitelikte bir materyaldir.

\section{Kalsiyum Fosforil Oligosakkaritleri:}

Kalsiyumun çözünebilir biyolojik bir formu olan kalsiyum fosforil oligosakkaridleri (POs-Ca) patates nişastasının enzimatik hidrolizasyonu sonucu elde edilir ve içerisindeki kalsiyum biyolojik olarak kullanılabilir niteliktedir. Bu nedenle şekersiz sakızlarda katkı maddesi olarak kullanılmaktadır. ${ }^{84}$

To-o ve arkadaşlarl, ${ }^{85}$ kalsiyum fosforil oligosakkaridleri içeren sakızların remineralizasyon üzerine etkilerini inceledikleri çalışmalarında, Pos-Ca içerikli sakızların ağız ortamında, serbest kalsiyum oranını arttırarak remineralizasyona katkıda bulunduğunu ve minenin yüzey altı lezyonlarında tekrar kristalleşmeyi sağladığını bildirmişlerdir. Ayrıca kalsiyum fosforil oligosakkaritleri ve florun beraber ilave edildiği ürünlerin yalnızca kalsiyum fosforil oligosakkaritleri içeren ürünlerle kıyaslandıklarında sinerjik etki göstererek remineralizasyona daha fazla katkı sağladıkları araştırmacılar tarafından ifade edilmiştir.

\section{Kalsiyum Karbonat $\left(\mathrm{CaCO}_{3}\right)$ :}

Kalsiyum karbonat $\left(\mathrm{CaCO}_{3}\right)$ diş macunlarında yaygın olarak abraziv olarak kullanılan alkali, tamponlayııı bir ajandır. Diş macunlarında sodyum monoflorofosfatla beraber kullanılmaktadır. ${ }^{86,87}$

Kalsiyum karbonat bazlı diş macunları, alkali pH değerine ve tamponlama kapasitesine sahip olsalar da çözünürlükleri nötral pH'da çok azdır. Bu özelliği kalsiyum karbonatın dental plak asidojenitesi üzerine olan etkisini sınırlamaktadır fakat Duke'a ${ }^{87}$ göre küçük partikülleri, kalsiyum karbonatlı diş macunlarından firçalamadan saatler sonra bile dental plakta depolanmaktadır. Asidik ortam oluştuğunda ise bu depolanan partiküllerin çözünürlüğü artmakta ve plak karyojenitesinin azaltımasında ve florun etkisinin potansiyelize edilmesinde rol oynamaktadır. Kalsiyum karbonatlı diş macunlarının silika bazı diş macunlarıyla kıyaslandığı bir başka çalışmada kalsiyum karbonatı diş macununun demineralizasyonu önlemede ve remineralizasyonu arttırmada daha etkili olduğu bildirilmiştir. ${ }^{87}$ Curry ve arkadaşlar ${ }^{88}$ kalsiyum karbonat ve CCP-ACP içerikli diş macunlarının demineralize diş dokuları üzerine etkilerini inceledikleri çalışmalarında, her iki diş macununun da remineralizasyon etkisinin olduğunu, bununla beraber CCP-ACP içerikli diş macununun anlamlı derecede daha fazla remineralizasyon sağladığını bildirmişlerdir. Çalışmalar kalsiyum karbonatın diş macunlarına ilavesinin remineralizasyon açısından olumlu sonuçlar verdiğini fakat yeni geliştirilen remineralizasyon ajanlarıla kıyaslanabilmesi amacıyla daha fazla çalışma yapılması gerektiğini göstermektedir.

\section{Sodyum Trimetafosfat (sTMP):}

Florlu diş macunlarının etkinliğini artırmak 
amacıyla, diş macunu içeriğine fosfat tuzlarının ilavesi uzun yıllardır kullanılan bir yöntemdir. Sodyum trimetafosfat, içerisinde bulunan sodyum ve fosfat iyonlarının yardımıyla flor içerikli diş macunlarının etkinliklerini arttırmak amacıyla en çok tercih edilen iyonlardan biridir. Birçok çalışma sTMP ilavesinin demineralizasyonu önlemede etkili olduğunu göstermektedir. ${ }^{89-92}$

Danelon ve arkadaşlarının ${ }^{90}$ sTMP ilaveli düşük flor içerikli preparatların başlangıç mine lezyonlarının remineralizasyonu üzerine olan etkilerini, yüksek flor içerikli preparatlarla kıyasladıkları çalışmalarında; sTMP ilavesinin düşük flor içerikli preparatların da yüksek flor içerikli preparatlar kadar başarılı olmasını sağladığı belirtilmiştir. Finn ve arkadaşlarının ${ }^{91} \% 1,5$ sTMP içerikli sakızları düzenli olarak çiğneyen çocuklarda, aproksimal çürük gelişimini 3 yıl boyunca in-vivo olarak değerlendirdikleri çalışmalarında, aproksimal yüzey çürüklerinin gelişiminde azalma olduğu bildirilmiştir. Bununla beraber sTMP ilave edilen 1000 ppm ve 1500 ppm flor içerikli diş macunları ile aynı oranda flor içeren fakat sTMP ilave edilmeyen diş macunlarının kıyaslandığı bir çalışmanın sonucunda; sTMP, yüksek flor içerikli preparatlarla kullanıldığında ilave etki göstermemektedir. ${ }^{91}$ Manarelli ve arkadaşları ${ }^{94}$ sTMP ve $\mathrm{NaF}$ un $(100 \mathrm{~g} \mathrm{~F} / \mathrm{ml})$ ağız çalkalama solusyonlarına ilave edildiğinde minenin demineralizasyonunu önlemede yarattığı etkileri değerlendirdikleri çalışmalarında, iki iyonun beraber kullanımının NaF'un tek başına kullanımından daha fazla koruyucu etki gösterdiğini bulmuşlardır.

Sonuç olarak sTMP demineralizasyonu önleyici ve remineralizasyonu arttırıc etkileri gösteren bir ajan olarak göze çarpmaktadır.

\section{SONUÇ}

Diş sert dokularının remineralizasyonunu sağlamak ve demineralizasyonu önlemek amacıyla günümüze kadar birçok araştırma yapılmıştır. Flor ve flor içerikli ürünler bu amaçla kullanılan en eski materyallerdir. Her ne kadar florun yaygın ve etkili kullanımı ile çürük insidansı azaltılabilse de tamamen ortadan kaldırılamamaktadır. Geliştirilen birçok remineralizasyon ajanı ve çürük önleyici ajanın farklı oranlarda olumlu etkileri bulunmaktadır. Son yıllarda bireysel ve profesyonel olarak kullanıma sunulan nanoteknoloji ile üretilmiş ve biyoaktif içerikli remineralizasyon ajanları ve çürük önleyici ajanlar ilerisi için umut verici bulunmaktadır.

\section{KAYNAKLAR}

1. Goswami M, Saha S, Chaitra TR. Latest developments in nonfluoridated remineralizing technologies. J Indian Soc Pedod Prev Dent 2012;30:2-6.

2. Lundeen T.F, Roberson T.M. Cariology: the lesion, etiology, prevention, and control. The Art and Science of Operative Dentistry. Third edition. s. 60128, Mosby, Missouri, 1995

3. Featherstone JDB. Remineralization, the Natural Caries Repair Process-The Need for New Approaches. Adv Dent Res 2009;21:4-7.

4. Featherstone JD. The science and practice of caries prevention. J Am Dent Assoc 2000;131:887-99.

5. Cochrane NJ, Cai F, Huq NL, Burrow MF, Reynolds EC. New approaches to enhanced remineralization of tooth enamel. J Dent Res 2010;89:1187-97.

6. Longbottom C, Ekstrand K, Zero D, Kambara M. Novel preventive treatment options. Monogr Oral Sci. 2009;21:156-63.

7. Moi GP, Tenuta LM, Cury JA. Anticaries potential of a fluoride mouthrinse evaluated in vitro by validated protocols. Braz Dent J 2008;19:91-6.

8. 8. Groeneveld A, Van Eck AA, Backer Dirks 0 . Fluoride in caries prevention: is the effect pre- or post-eruptive? J Dent Res 1990;69:751-5.

9. 9. Nalbantgil D, Oztoprak MO, Cakan DG, Bozkurt $\mathrm{K}$, Arun T. Prevention of demineralization around orthodontic brackets using two different fluoride varnishes. Eur J Dent 2013;7:41-7

10. Alsaffar A, Tantbirojn D, Versluis A, S. Beiraghi. Protective effect of pit and fissure sealants on demineralization of adjacent enamel. Pediatr Dent 2011;33:491-5.

11. Rodrigues E, Delbem AC, Pedrini D, Cavassan L. Enamel remineralization by fluoride-releasing materials: proposal of a pH-cycling model. Braz Dent J 2010;21:446-51.

12. Chu $\mathrm{CH}$, Edward CM. Microhardness of dentine in primary teeth after topical fluoride applications. J Dent 2008;36:387-91

13. Calvo AF, Tabchoury CP, Del Bel Cury AA, Tenuta LM, da Silva WJ, Cury JA. Effect of acidulated phosphate fluoride gel application time on enamel 
demineralization of deciduous and permanent teeth. Caries Res 2012;46:31-7.

14. Peng JJ, Botelho MG, Matinlinna JP. Silver compounds used in dentistry for caries management: a review. J Dent 2012;40:531-41

15. Zhi QH, Lo EC, Kwok AC. An in vitro study of silver and fluoride ions on remineralization of demineralized enamel and dentine. Aust Dent J 2013 Mar;58:50-6.

16. Mei ML, Li QL, Chu CH, Lo EC, Samaranayake LP. Antibacterial effects of silver diamine fluoride onmulti-species cariogenic biofilm on caries. Ann Clin Microbiol Antimicrob. 2013 Feb 26;12:4.

17. Cheng L, Zhang K, Weir MD, Liu H,Zhou X, Hockin $H$. Effects of antibacterial primers with quaternary ammonium and nano-silver on $\mathrm{S}$. mutans impregnated in human dentin blocks. Dent Mater 2013;29:462-72

18. Zhang K, Li F, Imazato S, Cheng L, Liu H. Dual antibacterial agents of nano-silver and 12methacryloyloxydodecylpyridinium bromide in dental adhesive to inhibit caries. J Biomed Mater Res B Appl BioMater 2013;101:929-38

19. Pecharki GD, Cury JA, · Paes Leme AF, Tabchoury CPM, - Del Bel Cury AA, Rosalen PL, Bowen WH. Effect of Sucrose Containing Iron (II) on Dental Biofilm and Enamel Demineralization in situ. Caries Res 2005;39:123-9

20. Devulapalle KS, Mooser G. Glucosyltransferase inactivationreduces dental caries. J Dent Res 2001;80:466-9.

21. Rosalen PL, Pearson SK, Bowen WH. Effects of iron and fluoride co-crystallized with sugar on cariesdevelopment and acid formation in desaliated rats. ArchOral Biol 1996;41:1003-10.

22. Martinhon CC, Italiani Fde M, Padilha Pde M, Bijella MF, Delbem AC, Buzalaf MA. Effect of iron on bovine enamel and on the composition of the dental biofilm formed in situ. Arch Oral Biol 2006;51:471-5

23. Alves KM, Franco KS, Sassaki KT, Buzalaf MA, Delbem AC. Effect of iron on enamel demineralization and remineralization in vitro. Arch Oral Biol 2011;56:1192-8.

24. Hidaka S, Okamoto Y, Abe K, Miyazaki K. Effects of indium and iron ions on in vitro calcium phosphate precipitationand crystallinity. J Biomed Mater Res 1996;31:11-8
25. Guggenbuhl P, Filmon R, Mabilleau G, Basle' MF, Chappard D. Iron inhibits hydroxyapatite crystal growth in vitro. Metabolism 2008;57:903-10.

26. Hedberg M, Hasslof $P$, Sjostrom I, Twetman S, Stecksen-Blicks C. Sugar fermentation in probiotic bacteria- an in vitro study. Oral Microbiol Immunol 2008;23:482-5.

27. Makinen KK, Saag M, Isotupa KP, Olak J, Nõmmela $R$, Söderling $E$, et al. Similarity of the effects of erythritol and xylitol on some risk factors of dental caries. Caries Res 2005;39:207-15.

28. Balakrishnan M, Simmonds RS, Tagg JR. Dental caries is a preventable infectious disease. Aust Dent J 2000;45:235-45.

29. Söderling $E$, Isokangas $P$, Pienihäkkinen $K$, Tenovuo J Influence of maternal xylitol consumption on acquisition of mutans streptococci by infants. J Dent Res 2000;79:882-7.

30. Loesche WJ The effect of sugar alcohols on plaque and saliva level of Streptococcus mutans. Swed Dent J 1984;8:125-35.

31. Bradshaw DJ, Marsh PD. Effect of sugar alcohols on the composition and metabolism of a mixed culture of oral bacteria grown in a chemostat. Caries Res 1994;28:251-6.

32. Gaffar A, Blake-Haskins JC, Sullivan R, Simone A, Schmidt $R$, Saunders F. Cariostatic effects of a xylitol/NaF dentifrice in vivo. Int Dent J 1998;48:32-9.

33. Van der Hoeven JS. Cariogenicity of disaccharide alcohols inrats. Caries Res 1980;14:61-6

34. Imfeld TN. Non-nutritive sweeteners, sugar substitutes, andconfectionery products. In: Identification of low caries risk dietarycomponents. Karger, Basel 1983, pp 117-4

35. Takatsuka T, Exterkate RA, ten Cate JM. Effects of Isomalt on enamel de- and remineralization, a combined in vitro pH-cycling model and in situ study. Clin Oral Investig. 2008;12:173-7

36. Hayes ML, Roberts KR. The breakdown of glucose, xylitol and other sugar alcohols by humandental plaque bacteria. Arch Oral Biol 1978;23:445-51.

37. Birkhed D, Edwardsson S, Kalfas S, Svensater G. Cariogenicity of sorbitol. Swed Dent J1984;8:14754.

38. Splieth $\mathrm{CH}$, Alkilzy M, Schmitt J, Berndt C, Welk A. Effect ox xylitol and sorbitol on plaque acidogenesis. Quintess Int; 2009;40:279-85 
39. Thorild I, Libndou B, Twetman S. Caries in 4-yearold children after maternal chewing of gums containing combinations of xylitol, sorbitol, chlorhexidine and fluoride. Eur Arch Paediatr Dent 2006;7:241-5

40. Shibasaki K, Sano H, Matsukubo T, Takaesu Y. Effects oflow molecular chitosan on $\mathrm{pH}$ changes in human dentalplaque. Bull Tokyo Dent Coll 1994;35:33-9.

41. Hayashi Y, Ohara N, Ganno T, Yamaguchi K, Ishizaki T, Nakamura T, Sato M. Chewing chitosancontaining gum effectively inhibits the growth of cariogenic bacteria. Arch Oral Biol 2007;52:290-4

42. Uysal T, Akkurt MD, Amasyali M, Ozcan S, Yagci A, Basak $F$, Sagdic D. Does a chitosan-containing dentifrice prevent demineralization around orthodontic brackets? Angle Orthod 2011;81:31925.

43. Arnaud TM, de Barros Neto B, Diniz FB.Chitosan effect on dental enamel de-remineralization: an in vitro evaluation. J Dent 2010;38:848-52

44. Muzzarelli R, Tarsi R, Filippini O, Giovanetti E, Biagini G,Varaldo PE. Antimicrobial properties of $\mathrm{N}$ carboxybutylchitosan. Antimicrob Agents Chemother. 1990;34:2019-23.

45. Fujiwara M, Hayashi $Y$, Ohara N. Inhibitory effect of watersoluble chitosan on growth of Streptococcus mutans. NewMicrobiol 2004;27:836.

46. Bae K, Jun EJ, Lee SM, Paik DI, Kim JB. Effect of watersolublereduced chitosan on Streptococcus mutans, plaqueregrowth and biofilm vitality. Clin Oral Investig. 2006;10:102-7.

47. Huang S, Gao S, Cheng L, Yu H. Combined effects of nano-hydroxyapatite and Galla chinensis on remineralisation of initial enamel lesion in vitro. J Dent 2010;38:811-9.

48. Chu JP, Li JY, Hao YQ, Zhou XD. Effect of compounds of Gallachinensis on remineralization of initial enamel cariouslesions in vitro. J Dent 2007;35:383-7.

49. .Cheng L, Li JY, Huang S, Zhou XD. Effect of Galla chinensis on enhancing remineralization of enamel crystals. Biomed Mater 2009;4:034103

50. Xie Q, Li JY, Zuo YL, Zhou XD. Hua Xi Kou Qiang Yi Xue Za Zhi. The effect of galla chinensis on the growth of cariogenic bacteria in vitro. West China Journal of Stomatology 2005;23:82-4
51. Huang X, Cheng L, Exterkate RA, Liu M, Zhou X, Li $J$, ten Cate JM. Effect of $\mathrm{pH}$ on Galla chinensis extract's stability and anti-caries properties in vitro. Arch Oral Biol 2012;57:1093-9.

52. Amaechi BT, Porteous N, Ramalingam K, Mensinkai PK, Ccahuana Vasquez RA, Sadeghpour A, Nakamoto T. Remineralization of Artificial Enamel Lesions by Theobromine. Caries Res 2013;47:399405.

53. Kargül B, Özcan M, Peker S, Nakamoto T, Simmons WB, Falster AU: Evaluation of human enamel surfaces treated with theobromine: a pilot study. Oral Health Prev Dent 2012; 10:275-82.

54. Nakamoto T, Simmons WB Jr, Falster AU: Productsof Apatite-Forming Systems. US Patentapplication number: US 5,919,426: 1999.http://patft.uspto.gov/netacgi/nphParser?Sect2 $=$ PTO1\&Sect2 $=$ HITOFF\&p $=1 \& \mathrm{u}=$ /netahtml/PTO/search-bool.html\&r = 1\&f =G\&l = $50 \& d=$ PALL\&RefSrch $=$ yes\&Query $=$ PN/5919426

55. Nakamoto T, Simmons WB Jr, Falster AU: ApatiteForming Systems: Methods and Products.US Patent application number: US 6,183,711B1; 2001. http://patft.uspto.gov/netacgi/nph-Parser?Sect2 = PTO1\&Sect2 = HITOFF\&p =1\&u= /netahtml/PTO/search-bool.html\&r =1\&f = G\&l = $50 \& d=$ PALL\&RefSrch $=$ yes\&-Query = PN/6183711.

56. Ceyhan T, Günay V, Çapoğlu A, Sayrak H,Karaca C. Production and characterization of a glassceramic biomaterial and in vitro and in vivo evaluation of its biological effects. Acta Orthop Traumatol Turc 2007;41:307-13.

57. Hassanein OE, El-Brolossy TA. An investigation about the remineralization potential of bio-active glass on artificially carious enamel and dentin using Raman spectroscopy. Egypt J Solids 2006;29:6980.

58. Forsback AP, Areva S, Salonen JI. Mineralization of dentin induced by treatment with bioactive glass S53P4 in-vitro. Acta Odont Scand 2004;62:14-20.

59. Burwell AK, Litkowski L, Greenspan DC. Calcium sodium phosphosilicate (NovaMin): remineralization potential. Adv Dent Res 2009;21:35-9.

60. Vahid Golpayegani M, Sohrabi A, Biria M, Ansari G. Remineralization Effect of Topical NovaMin Versus Sodium Fluoride $(1.1 \%)$ on Caries-Like Lesions in Permanent Teeth. J Dent 2012;9:68-75. 
61. Diamanti I, Koletsi-Kounari H, Mamai-Homata E, Vougiouklakis G. In vitro evaluation of fluoride and calcium sodium phosphosilicate toothpastes, on root dentine caries lesions.J Dent 2011;39:619-28.

62. Prabhakar AR, Arali V. Comparison of the remineralizing effects of sodium fluoride and bioactive glass using bioerodible gel systems. J Dent Res Dent Clin Dent Prospects. 2009;3:117-21.

63. Yli-Urpo H, Närhi T, Söderling E. Antimicrobial effects of glass ionomer cements containing bioactive glass (S53P4) on oral micro-organisms in vitro. Acta Odontol Scand. 2003;6:241-6.

64. Chiang YC, Chen HJ, Liu HC, Kang SH, Lee BS, Lin $\mathrm{FH}$, Lin HP, Lin CP. A novel mesoporous biomaterial for treating dentin hypersensitivity. J Dent Res 2010;89:236-40.

65. Wang Y, Li X, Chang J, Wu C, Deng Y. Effect of tricalcium silicate $(\mathrm{Ca}(3) \mathrm{SiO}(5))$ bioactive material on reducing enamel demineralization: an in vitro pH-cycling study. J Dent 2012;40:1119-26.

66. Dong Z, Chang J, Deng Y, Joiner A. Tricalcium silicate induced mineralization for occlusion of dentinal tubules. Aust Dent J 2011;56:175-80.

67. Onuma K, Yamagishi K, Oyane A: Nucleation and growth of hydroxyapatite nanocrystals for nondestructive repair of early caries lesions. J Cryst Growth 2005;282:199-207.

68. Lee JJ, Lee YK, Choi BJ, Lee JH, Choi HJ, Son HK, Hwang JW, Kim SO. Physical properties of resinreinforced glass ionomer cement modified with micro and nano-hydroxyapatite. J Nanosci Nanotechnol. 2010;10:5270-6.

69. Huang Sb, Gao SS, Yu HY, Effect of nanohydroxyapatite concentration on remineralization of initial enamel lesion in vitro. Biomed Mater 2009;4:55-9.

70. Tschoppe P, Zandim DL, Martus P, Kielbassa AM. Enamel and dentine remineralization by nanohydroxyapatitetoothpastes. J Dent 2011;6:430-7

71. Huang S, Gao S, Cheng L, Yu H. Remineralization potential of nano-hydroxyapatite on initial enamel lesions: an in vitro study. Caries Res 2011;45:4608.

72. Swarup JS, Rao A. Enamel surface remineralization: Using synthetic nanohydroxyapatite. Contemp Clin Dent 2012;3:433-6.
73. Çelik EU, Yazkan B, Katırcı G. Başlangıç çürük lezyonlarının tedavisi. Atatürk Üniv Dis Hek Fak Derg. 2011;1:48-56

74. Reynolds EC, Cai F, Shen P, Walker GD. Retention in plaque and remineralization of enamel lesions by various forms of calcium in a mouthrinse or sugarfree chewing gum. J Dent Res 2003;82:206-11.

75. Rahiotis C, Vougiouklakis G. Effect of a CPP-ACP agent on the demineralization and remineralization of dentine in vitro. J Dent 2007;35:695-8.

76. Reynolds EC, Cain CJ, Webber FL. Anticariogenecity of calcium phosphate complexes of tryptic casein phosphopeptides in the rat. J Dent Res 1995;74:1272-9

77. Cochrane NJ, Saranathan S, Cai F, Cross KJ, Reynolds EJ Enamel subsurface remineralization with casein phosphopeptides stabilized solution of calcium, phosphate and fluorid. Caries Res 2008;42:88-97

78. Karlinsey RL. US Provisional patent 2007017822. Materials and methods for manufacturing amorphous tricalcium phosphate and metal oxide alloys of amorphous tricalcium phosphate and methods of using the same

79. Karlinsey RL, Mackey AC. Solid-state preparation and dental bapplication of an organically modified calcium phosphate. J Material Sci.2009;44:346-349

80. Vogel GL, Zhang Z, Carey CM, Ly A, Chow LC, Proskin HM. Composition of plaque and saliva following a sucrose challenge and use of an alphatricalcium-phosphate-containing chewing gum. J Dent Res 1998;77:518-24.

81. Brunton PA, Davies RP, Burke JL, Smith A, Aggeli A, Brookes SJ, Kirkham J. Treatment of early caries lesions using biomimetic self-assembling peptides a clinical safety trial. Br Dent J 2013;215:E6.

82. Sullivan RJ, Charig A, Blake-Haskins J, Zhang YP, Miller SM, Strannick M, Gaffar A, Margolis HC. In vivo detection of calcium from dicalcium phosphate dihydrate dentifrices in demineralized human enamel and plaque. Adv Dent Res 1997;11:380-7.

83. Wefel JS, Harless JD. The use of saturated DCPD in remineralization of artificial caries lesions in vitro. J Dent Res 1987;66:1640-3.

84. Zhang YP, Din CS, Miller S, Nathoo SA, Gaffar A. Intraoral remineralization of enamel with a MFP/DCPD and MFP/ silica dentifrice using surface microhardness. J Clin Dent 1995;6:148-53. 
85. Kitasako Y, Tanaka M, Sadr A, Hamba H, Ikeda M, Tagami J. Effects of a chewing gum containing phosphoryloligosaccharides of calcium (POs-Ca) and fluoride onremineralization and crystallization of enamel subsurfacelesions in situ. J Dent 2011;39:771-9

86. To-o K, Kamasaka H, Nishimura T, Kuriki T, Saeki S,Nakabou Y. Absorbability of calcium from calcium-boundphosphoryl oligosaccharides in comparison with that from various calcium compounds in the rat ligated jejunum loop. Bioscience Biotechnology and Biochemistry 2003;67:1713-8.

87. Duke SA. Effect induced by a chalk-based toothpaste on the $\mathrm{pH}$ changes of plaque challenged by a high sugar diet over an8-hour period.Caries Res 1986;20:381-4.

88. Cury JA, Simões GS, Del Bel Cury AA, Gonçalves NC, Tabchoury CP. Effect of a calcium carbonatebased dentifrice on in situ enamel remineralization. Caries Res 2005;39:255-7.

89. Curry JA, Francisco SB, Simões GS, Del Bel Cury $A A$, Tabchoury CPM: Effect of a calcium carbonate-based dentifrice on enamel demineralization in situ. Caries Res 2003;37:194-9.

90. Danelon M, Takeshita EM, Sassaki KT, Delbem AC. In situ evaluation of a low fluoride concentration gel with sodium trimetaphosphate in enamel remineralization. Am J Dent 2013 Feb;26:15-20.

91. Finn SB, Frew RA, Leibowitz R, Morse W, Man-sonHing $L$, Brunelle J: The effect of sodium trimetaphosphate (TMP) as a chewing gum additive on caries increments in children. J Am Dent Assoc 1978;96:651-5.

92. O'Mullane DM, Kavanagh D, Ellwood RP, Chesters RK, Schafer F, Huntington E, Jones PR: A threeyear clinical trial of a combination of trimetaphosphate and sodium fluoride in silica toothpaste. J Dent Res 1997;76:1776-81.

\section{Yazışma Adresi:}

Selçuk Savaş

İzmir Kâtip Çelebi Üniversitesi

Diş Hekimliği Fakültesi Pedodonti AD

Aydınlık Evler Mahallesi, Cemil Meriç

Caddesi, 6780 Sokak. No:48, 35640-Çiğli /

İZMİR

Tel: +90 (232) 3254040

Fax: +90 (232) 3252535

e-mail: selcuksavas1983@hotmail.com 